\title{
Education and Attitudes toward Interpersonal and State-Sanctioned Violence
}

Landon Schnabel, Indiana University, Bloomington

ABSTRACT The link between education and liberal attitudes is among the most consistent findings in public-opinion research, but the theoretical explanations for this relationship warrant additional attention. Previous work suggested that the relationship is due to education socializing students to the "official culture" of the United States. This study uses the World Values Survey and General Social Survey to examine Americans' attitudes toward the justifiability of violence. I find that Americans with more education are less likely to say that interpersonal violence-against women, children, and other individuals-can be justifiable. However, they are more likely to say that state-sanctioned violence-war and police violence-can be justifiable. These patterns are consistent with a modified socialization model of education and social attitudes. I conclude that American education socializes people to establishment culture, identity, and interests, which differentiate between unacceptable interpersonal violence and ostensibly acceptable state-sanctioned violence.

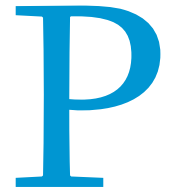
ublic-opinion research seeks to understand the social forces that shape peoples' beliefs, values, and identities, and education has long been one of the most used and most consistent predictors of social attitudes (Bobo and Licari 1989; Brooks 2006; Hyman and Wright 1979; Kingston et al. 2003; Page and Shapiro 1992; Schnabel and Sevell 2017; Selznick and Steinberg 1969; Smith 1995; Stouffer 1955; Weakliem 2002; Weil 1985). This study considers two key theories, development and socialization, that attempt to explain how education shapes social attitudes. I modify and test these competing theories on attitudes toward violence in the United States.

In the personal development model, education fundamentally changes people and their character so that they are more tolerant, more supportive of democratic values, and less authoritarian (e.g., Adorno et al. 1950). In the traditional socialization model, education socializes students to the "official culture" of individualism, libertarianism, and antiauthoritarianism (e.g., Phelan et al. 1995). Yet, acceptance for state violence persists in the United States despite increasing levels of education that are thought to promote liberal values and antiauthoritarianism. Although some vocal opponents of police brutality have been highly educated

Landon Schnabel is a PhD candidate in sociology at Indiana University. He can be reached at lpschnab@indiana.edu. people, we do not know whether the average college-educated American is more likely to oppose police violence than those with less education who are more likely to face the consequences of state-sanctioned violence (e.g., experience police brutality or fight in wars).

The apparent acquiescence of much of the American public to state violence motivates a test and possible refinement of previous theories. I set forth a refined socialization model, which builds on Jackman's argument that education can promote dominant interests and legitimate injustice, at least in the United States (Jackman 1994; Jackman and Muha 1984). I argue that education does not have a uniform antiauthoritarian effect; instead, American education socializes students to establishment culture and interests that are both anti-welfare and pro-policing.

\section{EDUCATION AND ATTITUDES}

Although the education-as-development model for the relationship between education and attitudes was the traditional view held by foundational social psychologists and public-opinion researchers (e.g., Adorno et al. 1950; Rokeach 1960; Stouffer 1955), key work has since found greater support for an education-as-socialization model (e.g., Phelan et al. 1995; Selznick and Steinberg 1969; Stubager 2008; Weil 1985). For example, Phelan and colleagues (1995) leveraged a few distinct attitudes toward homelessness to show that-consistent with the socialization model-education is 
positively associated with tolerance and support for civil liberties for homeless people ${ }^{1}$ but negatively associated with support for economic aid to them. Phelan et al. (1995) argued that the "educational system is the primary vehicle through which the 'official' or 'ideal' culture is transmitted to citizens" (p. 130). According to them, the official culture of the United States emphasizes tolerance, individualism, and the myth of meritocracy.

The socialization model has proven effective, and Stubager $(2008 ; 2009 ; 2010 ; 2013)$ considered and confirmed it repeatedly in a Scandinavian context. In the process, he applied identity theory (see, e.g., Brenner, Serpe, and Stryker 2014; Stets and Serpe 2013; Stryker 2008; Tajfel 1978) and introduced a new focus on socialization into not only "official culture" but also group identity and consciousness. According to Stubager, schooling produces an educated identity characterized by consistent libertarianism and antiauthoritarianism.

\section{Developmental Model and Previous Socialization Model}

Those with more education condemn violence by any group, including the state, because schooling promotes personal development of a consistent ethical frame (i.e., the developmental model) and promotes libertarianism while countering authoritarianism (i.e., the previous socialization model).

\section{Proposed Socialization Model}

Those with more education condemn interpersonal violence but accept some forms of state-sanctioned violence because schooling socializes people to establishment culture, identity, and interests, thereby legitimating ruling authority and its actions.

\section{METHODS}

To adjudicate between these possibilities, this study used US data from the World Values Survey (WVS) and the General Social

\section{In a refinement and new application of the theory, I considered and tested whether education can socialize students into not only "official culture" and antiauthoritarian identity but also establishment identity, values, and interests.}

In a refinement and new application of the theory, I considered and tested whether education can socialize students into not only "official culture" and antiauthoritarian identity but also establishment identity, values, and interests. In other words, I examined whether American education may be associated with preference for the educated ruling class on issues of both redistribution as Phelan and colleagues (1995) demonstrated and state-sanctioned violence that protects and extends the interests of the ruling class. Therefore, rather than the blanket anti-statism highlighted by Phelan et al. (1995) and antiauthoritarianism highlighted by Stubager (2008), I suggest that education may yield issue- and context-specific pro-statism in the interest of the purportedly meritocratic ruling class (Jackman 1994; Jackman and Muha 1984). A subsection of highly educated Americans has vocally opposed state-sanctioned violence, but what does the average college-educated American think about state-sanctioned violence (e.g., police brutality against racial minorities, war, and torture) that does not negatively affect people like them and which could be seen as upholding their interests? Support for-or at least complacency toward-state-sanctioned violence among the growing college-educated population in the United States could help explain why Americans have not put an end to ethically problematic state violence (e.g., police brutality or the torture carried out at Guantanamo Bay).

To apply this refinement of the socialization model, this study examined attitudes toward different types of violence-namely, interpersonal versus state-sanctioned violence. (On the importance of testing whether different related attitudes operate differently, see Gibson 2013.) Some factors, such as gender, are known to be consistent predictors of attitudes toward violence. As Smith (1984) showed, women are consistently more opposed to violence across surveys and types of violence. Education may demonstrate a similar pattern in keeping with the developmental model and previous socialization model or, consistent with my refinement of the socialization model, different patterns could emerge.
Survey (GSS). The WVS is a cross-national and nationally representative survey of basic values and beliefs. I used US data from the sixth wave (2010-2014) of the WVS, which provide information on education, key covariates, and attitudes toward interpersonal and state-sanctioned violence. The interpersonal-violence measures were preceded by the following directions: "Please tell me for each of the following actions whether you think it can always be justified, never be justified, or something in between." The response options for these justifiability-of-violence measures-"for a man to beat his wife," "parents beating children," and "violence against other people"-ranged from 1 ("never justifiable") to 10 ("always justifiable"). The justifiability-of-state-sanctioned-violence measure asked the following: "Do you agree or disagree with the following statement: Under some conditions, war is necessary to obtain justice.” Table 1 lists descriptive statistics.

The GSS, a nationally representative survey of Americans, is one of the most widely used and trusted surveys in social-scientific research (Smith et al. 2015). I used cross-sectional data from the 2010, 2012, and 2014 surveys, which provided information on education, covariates that parallel the WVS data, and measures of interpersonal and state-sanctioned violence. The measure of interpersonal violence asked, "Do you strongly agree, agree, disagree, or strongly disagree that it is sometimes necessary to discipline a child with a good, hard spanking?" The measure of state-sanctioned violence asked, "Are there any situations you can imagine in which you would approve of a policeman striking an adult male citizen?" The response options were yes and no.

Highest educational degree attained was the key predictor for both the WVS and GSS, and I included covariates drawn from previous research (e.g., Phelan et al. 1995) and available in comparable form in both the WVS and GSS. I present a series of models in which I continued to add relevant covariates that could account for any relationship between education and attitudes. I started with a bivariate model of the impact of education on attitudes, then added key sociodemographic characteristics, then measures of political 
views and party identification, then family income (measured as self-placement on a 10-point scale in the WVS and as total family income in the GSS), and finally mother's and father's education (which are only available in the GSS). These measures were added
Americans with more education are less likely to think that intimate-partner violence, violence against children, and violence against other people can be justifiable. ${ }^{3}$ However, education is positively associated with the belief that war is sometimes necessary.

\section{This pattern of more highly educated people believing in the justifiability of state-sanctioned violence was consistent with a modified socialization model in which people learn to hold establishment values that legitimate state-sanctioned violence.}

to consider whether education differences result from education itself or other factors, such as race and socioeconomic status (SES), which are highly correlated with education.

The samples were constrained to the cases for which each of the outcome measures and education were all available; missing data on covariates were handled with multiple imputation. I used binary logistic regression for the binary outcomes and ordinary least squares (OLS) for other outcomes. The patterns were not sensitive to the models used: sensitivity analyses with Alternating Least Squares Optimized Scaling (ALSOS; these results are included in the supplement), ${ }^{2}$ ordinal logistic regression models, and multinomial logistic regression models yielded equivalent patterns.

\section{RESULTS}

\section{US World Values Survey Analyses}

Table 2 shows US World Values Survey results on whether interpersonal and state-sanctioned violence can ever be justifiable.
This pattern of more highly educated people believing in the justifiability of state-sanctioned violence is consistent with a modified socialization model in which people learn to hold establishment values that legitimate state-sanctioned violence.

The patterns for covariates (not shown) were consistent with previous research. Women were less supportive of violence across measures. Being non-Latinx white had a similar impact to having more education: non-Latinx blacks, Latinxs, and people in the "other race" category were more likely than whites to say that interpersonal violence can be justified but less likely to believe in necessary war. These patterns suggest further support for a modified socialization model of attitudes in which establishment people (i.e., highly educated white men) espouse the establishment value of state-sanctioned violence being justifiable.

The general pattern for education persisted despite sometimes smaller coefficients as various covariates were added to the model. The most notable general attenuation of the impact of education

Table 1

Descriptive Statistics for Key Measures

\begin{tabular}{|c|c|c|c|c|}
\hline & Description & Mean & SD & Range \\
\hline \multicolumn{5}{|l|}{ World Values Survey US Data $(\mathrm{N}=2,147)$} \\
\hline Beating Wife Ever Justifiable & For a man to beat his wife: Never justifiable $=1$ to always justifiable $=10$ & 1.45 & 1.47 & $1-10$ \\
\hline Beating Children Ever Justifiable & Parents beating children: Never justifiable $=1$ to always justifiable $=10$ & 1.80 & 1.83 & $1-10$ \\
\hline Violence Against Other People Ever Justifiable & Violence against other people: Never justifiable $=1$ to always justifiable $=10$ & 2.05 & 1.92 & $1-10$ \\
\hline War Ever Justifiable & Under some conditions, war is necessary to obtain justice $=1$ & 0.74 & & \\
\hline \multicolumn{5}{|l|}{ Education } \\
\hline Less Than High School & $<\mathrm{HS}=1$ & 0.11 & & \\
\hline High School & $\mathrm{HS}=1$ & 0.51 & & \\
\hline Associate/Junior College & Associate/Junior College=1 & 0.09 & & \\
\hline Bachelor's Degree & Bachelor's=1 & 0.17 & & \\
\hline Graduate Degree & Graduate $=1$ & 0.12 & & \\
\hline \multicolumn{5}{|l|}{ General Social Survey $(N=2,121)$} \\
\hline Spanking Children Justifiable & $\begin{array}{l}\text { Strongly disagree }=1 \text { to strongly agree }=4 \text { it is sometimes necessary } \\
\text { to discipline a child with a good hard spanking }\end{array}$ & 2.81 & 0.86 & $1-4$ \\
\hline Police Striking Citizen Justifiable & Ever approve of police striking citizen=1 & 0.65 & & \\
\hline \multicolumn{5}{|l|}{ Education } \\
\hline Less than High School & $<\mathrm{HS}=1$ & 0.14 & & \\
\hline High School & $\mathrm{HS}=1$ & 0.49 & & \\
\hline Associate/Junior College & Associate/Junior College=1 & 0.08 & & \\
\hline Bachelor's Degree & Bachelor's=1 & 0.18 & & \\
\hline Graduate Degree & Graduate $=1$ & 0.10 & & \\
\hline
\end{tabular}


Table 2

\section{Education Predicting Justifiability of Violence, US World Values Survey}

\begin{tabular}{|c|c|c|c|c|}
\hline & Bivariate & With Demographics & With Politics & With Family Income \\
\hline \multicolumn{5}{|l|}{ Beating Wife Ever Justifiable (OLS) } \\
\hline Less than High School & - & - & - & - \\
\hline \multirow[t]{2}{*}{ High School } & $-0.56 * * *$ & $-0.44 * * *$ & $-0.42 * * *$ & $-0.46 * * *$ \\
\hline & $(0.10)$ & $(0.11)$ & $(0.11)$ & $(0.11)$ \\
\hline \multirow[t]{2}{*}{ Associate/Junior College } & $-0.74 * * *$ & $-0.63^{* * *}$ & $-0.61^{* * *}$ & $-0.68 * * *$ \\
\hline & $(0.14)$ & $(0.14)$ & $(0.14)$ & $(0.14)$ \\
\hline \multirow[t]{2}{*}{ Bachelor's Degree } & $-0.80 * * *$ & $-0.68 * * *$ & $-0.64 * * *$ & $-0.79 * * *$ \\
\hline & $(0.12)$ & $(0.13)$ & $(0.13)$ & $(0.13)$ \\
\hline \multirow[t]{2}{*}{ Graduate Degree } & $-0.83^{* * *}$ & $-0.65^{* * *}$ & $-0.59 * * *$ & $-0.84 * * *$ \\
\hline & $(0.13)$ & $(0.13)$ & $(0.13)$ & $(0.14)$ \\
\hline \multicolumn{5}{|l|}{ Beating Children Ever Justifiable (OLS) } \\
\hline Less than High School & - & - & - & - \\
\hline \multirow[t]{2}{*}{ High School } & $-0.48 * * *$ & $-0.31^{*}$ & $-0.28^{*}$ & $-0.32^{*}$ \\
\hline & $(0.13)$ & $(0.13)$ & $(0.13)$ & $(0.13)$ \\
\hline \multirow[t]{2}{*}{ Associate/Junior College } & $-0.75^{* * *}$ & $-0.57 * *$ & $-0.55^{* *}$ & $-0.62 * * *$ \\
\hline & $(0.18)$ & $(0.18)$ & $(0.18)$ & $(0.18)$ \\
\hline \multirow[t]{2}{*}{ Bachelor's Degree } & $-0.74^{* * *}$ & $-0.54^{* *}$ & $-0.50 * *$ & $-0.64 * * *$ \\
\hline & $(0.15)$ & $(0.15)$ & $(0.15)$ & $(0.16)$ \\
\hline \multirow[t]{2}{*}{ Graduate Degree } & $-0.75^{* * *}$ & $-0.53^{* *}$ & $-0.48^{* *}$ & $-0.71^{* * *}$ \\
\hline & $(0.16)$ & $(0.16)$ & $(0.16)$ & $(0.17)$ \\
\hline \multicolumn{5}{|c|}{ Violence Against Other People Ever Justifiable (OLS) } \\
\hline Less than High School & - & - & - & - \\
\hline \multirow[t]{2}{*}{ High School } & $-0.36 * *$ & $-0.36^{* *}$ & $-0.36^{* *}$ & $-0.40 * *$ \\
\hline & $(0.14)$ & $(0.14)$ & $(0.14)$ & $(0.14)$ \\
\hline \multirow[t]{2}{*}{ Associate/Junior College } & $-0.58^{* *}$ & $-0.59 * *$ & $-0.59 * *$ & $-0.67^{* * *}$ \\
\hline & $(0.19)$ & $(0.19)$ & $(0.19)$ & $(0.19)$ \\
\hline \multirow[t]{2}{*}{ Bachelor's Degree } & $-0.54 * * *$ & $-0.57^{* * *}$ & $-0.54^{* * *}$ & $-0.70 * * *$ \\
\hline & $(0.16)$ & $(0.16)$ & $(0.16)$ & $(0.17)$ \\
\hline \multirow[t]{2}{*}{ Graduate Degree } & $-0.75^{* * *}$ & $-0.69 * * *$ & $-0.63 * * *$ & $-0.87 * * *$ \\
\hline & $(0.17)$ & $(0.17)$ & $(0.17)$ & $(0.18)$ \\
\hline \multicolumn{5}{|c|}{ War Ever Justifiable (Logistic Regression) } \\
\hline Less than High School & - & - & - & - \\
\hline \multirow[t]{2}{*}{ High School } & $0.78^{* * *}$ & $0.39 *$ & $0.32 *$ & $0.31^{\dagger}$ \\
\hline & $(0.15)$ & $(0.16)$ & $(0.16)$ & $(0.16)$ \\
\hline \multirow[t]{2}{*}{ Associate/Junior College } & $0.91^{* * *}$ & $0.46^{*}$ & $0.40^{+}$ & 0.37 \\
\hline & $(0.22)$ & $(0.23)$ & $(0.23)$ & $(0.24)$ \\
\hline \multirow[t]{2}{*}{ Bachelor's Degree } & $1.14^{* * *}$ & $0.66^{* * *}$ & $0.63^{* *}$ & $0.57^{* *}$ \\
\hline & $(0.19)$ & $(0.20)$ & $(0.21)$ & $(0.21)$ \\
\hline \multirow[t]{2}{*}{ Graduate Degree } & $1.00 * * *$ & $0.52^{*}$ & $0.53^{*}$ & $0.44 t$ \\
\hline & $(0.20)$ & $(0.21)$ & $(0.22)$ & $(0.23)$ \\
\hline N & 2,147 & 2,147 & 2,147 & 2,147 \\
\hline
\end{tabular}

Source: World Values Survey, Wave 6 (2010-2014)

Standard errors are in parentheses.

Notes: Demographics model adds gender, race/ethnicity, age, region, marital status, and parental status. Politics adds political views and party identification (all previous covariates are retained when covariates are added to sequential models). Family income adds self-placement on a 10-point income scale.

${ }^{\dagger} p<0.1,{ }^{*} p<0.05,{ }^{* *} p<0.01,{ }^{* * *} p<0.001$. 
was present in the model that added sociodemographic covariates, such as gender and race. Politics and family income did not account for the education pattern; in fact, the impact of education was generally similar to the bivariate pattern once family income (measured as self-placement on a subjective 10-point scale of incomes) was in the model. Therefore, the impact of education appears to be operating independent of SES.

\section{US General Social Survey Analyses}

Table 3 presents parallel results for the GSS on measures of interpersonal violence (i.e., whether corporal punishment can be necessary) and state-sanctioned violence (i.e., whether police violence racial categories is generally the inverse of those for education. ${ }^{4}$ Therefore, it again tended to be highly educated white men who espoused the establishment value of state-sanctioned violence. The general patterns again persisted although they were somewhat attenuated as other covariates were added to the models. Some of these covariates (e.g., income) were deeply intertwined with education and could be pathways by which education influences attitudes. 5

In both datasets, the impact of more educational degrees was typically ordered, with additional degrees making people increasingly different from those who did not finish high school. However, that was not the case for graduate education and attitudes

\section{American education, therefore, appears to promote an establishment politics that differentiates between unacceptable interpersonal violence and ostensibly acceptable state-sanctioned violence.}

can be necessary). Similar to WVS patterns, Americans with more education were less likely to say that parents hitting children is justifiable but more likely to say that police hitting citizens is justifiable. Again, women tended to be against both interpersonal and state-sanctioned violence, and the impact of nonwhite toward state-sanctioned violence. Whereas more education appears to consistently socialize people into establishment values up through a bachelor's degree, graduate education appears to function somewhat differently: some types of graduate education may promote antiestablishment values. ${ }^{6}$

Table 3

\section{Education Predicting Justifiability of Violence, US General Social Survey}

\begin{tabular}{|c|c|c|c|c|c|}
\hline & Bivariate & With Demographics & With Politics & With Family Income & With Parents' Education \\
\hline \multicolumn{6}{|l|}{ Spanking Children Justifiable (OLS) } \\
\hline Less than High School & - & - & - & - & - \\
\hline \multirow[t]{2}{*}{ High School } & 0.03 & 0.01 & -0.01 & 0.00 & 0.02 \\
\hline & $(0.06)$ & $(0.06)$ & $(0.05)$ & $(0.06)$ & $(0.06)$ \\
\hline \multirow[t]{2}{*}{ Associate/Junior College } & 0.01 & -0.01 & -0.03 & -0.01 & 0.02 \\
\hline & $(0.08)$ & $(0.08)$ & $(0.08)$ & $(0.08)$ & $(0.08)$ \\
\hline \multirow[t]{2}{*}{ Bachelor's Degree } & $-0.20 * *$ & $-0.20 * *$ & $-0.20 * *$ & $-0.17^{*}$ & -0.11 \\
\hline & $(0.06)$ & $(0.07)$ & $(0.07)$ & $(0.07)$ & $(0.07)$ \\
\hline \multirow[t]{2}{*}{ Graduate Degree } & $-0.39 * * *$ & $-0.39 * * *$ & $-0.34 * * *$ & $-0.30 * * *$ & $-0.23 * *$ \\
\hline & $(0.08)$ & $(0.08)$ & $(0.08)$ & $(0.08)$ & $(0.08)$ \\
\hline \multicolumn{6}{|c|}{ Police Striking Citizen Justifiable (Logistic Regression) } \\
\hline Less than High School & - & - & - & - & - \\
\hline \multirow[t]{2}{*}{ High School } & $1.05^{* * *}$ & $0.86^{* * *}$ & $0.82^{* * *}$ & $0.78^{* * *}$ & $0.73^{* * *}$ \\
\hline & $(0.13)$ & $(0.15)$ & $(0.15)$ & $(0.15)$ & $(0.15)$ \\
\hline \multirow[t]{2}{*}{ Associate/Junior College } & $1.25^{* * *}$ & $1.11^{* * *}$ & $1.08^{* * *}$ & $1.03^{* * *}$ & $0.94^{* * *}$ \\
\hline & $(0.21)$ & $(0.22)$ & $(0.22)$ & $(0.22)$ & $(0.23)$ \\
\hline \multirow[t]{2}{*}{ Bachelor's Degree } & $1.98^{* * *}$ & $1.71^{* * *}$ & $1.68^{* * *}$ & $1.58^{* * *}$ & $1.42^{* * *}$ \\
\hline & $(0.18)$ & $(0.19)$ & $(0.19)$ & $(0.20)$ & $(0.21)$ \\
\hline \multirow[t]{2}{*}{ Graduate Degree } & $1.62^{* * *}$ & $1.37 * * *$ & $1.39 * * *$ & $1.24 * * *$ & $1.03^{* * *}$ \\
\hline & $(0.20)$ & $(0.21)$ & $(0.22)$ & $(0.23)$ & $(0.24)$ \\
\hline N & 2,121 & 2,121 & 2,121 & 2,121 & 2,121 \\
\hline
\end{tabular}

Source: General Social Survey, 2010-2014.

Standard errors are in parentheses.

Notes: All models include binaries for survey year. Demographics model adds gender, race/ethnicity, age, region, marital status, and parental status. Politics adds political views and party identification (all previous covariates are retained when covariates are added to sequential models). Family income adds inflation-adjusted family income. Parents' education adds mother's and father's education.

${ }^{\dagger} p<0.1,{ }^{*} p<0.05,{ }^{* *} p<0.01,{ }^{* * *} p<0.001$ 
Readers may note that in both datasets the interpersonalviolence variables are ordered measures whereas the statesanctioned violence measures are binary. I conducted additional analyses in which I dichotomized the ordered measures to better parallel the binary measures and make effect sizes more comparable. Supplemental figures $\mathrm{S}_{1}$ and $\mathrm{S} 2$ present predicted probabilities with controls held at global means that demonstrate the same pattern of more education decreasing support for interpersonal violence and increasing support for state-sanctioned violence-with a decrease in support for state-sanctioned violence among those with graduate degrees. Education tends to have a substantial impact on these attitudes. For example, Americans with less than a high school education were approximately three times as likely to find wife beating sometimes justifiable (i.e., predicted probability of o.15) than those with a graduate degree (i.e., predicted probability of 0.04).

\section{DISCUSSION}

This study proposed a modified socialization model for how education shapes attitudes and applied it to Americans' beliefs about which types of violence are justifiable. The development model and previous socialization model both predicted that education would lead people to think that violence by individuals and by the state is not justifiable. However, the results were consistent with my modified socialization model, which suggests that not only does education transmit individualistic and meritocratic libertarian values, it also can promote establishment interests (Jackman 1994; Jackman and Muha 1984). Americans with more education were less likely to say that interpersonal violence-against women, against children, and against other Americans-can be justifiable. However, they were more likely to say that state-sanctioned violence-war and police violence-can be justifiable. American education, therefore, appears to promote an establishment politics that differentiates between unacceptable interpersonal violence and ostensibly acceptable state-sanctioned violence.

This brief study provides support for Phelan et al. (1995) and others who argued that education socializes people to an "official culture"; however, it suggests that the American official culture is not purely libertarian and that education is more than a medium for the transmission of a set of ruling-class values. As Stubager $(2008 ; 2009$; 2013) suggested, it is also an identitybuilding process. Breaking slightly from Stubager, however, I found that Americans with more education take on the values and interests of the educated class who gain from libertarian economics and government intervention to protect their interests (Jackman 1994; Jackman and Muha 1984).

Although attitudes toward violence were the specific case for a broader question about education and public opinion, these specific attitudes are important and timely in their own right. Based on popular assumptions, we might assume that American support for police brutality against citizens is most pronounced among certain uneducated groups (e.g., uneducated white men). However, in fact, belief in the justifiability of police violence extends to and appears to be especially strong among those with higher levels of education (and especially college-educated white men). Therefore, it appears to be those higher-class people most insulated from the risk of experiencing police violence-or having to go to war themselves-who were most likely to say that state-sanctioned violence might be necessary. Future research should examine further the particular conditions under which people of different educational levels would consider police violence and war justifiable.7
Similar to how Phelan and colleagues (1995) improved on previous research by differentiating between social and economic values to substantiate a socialization model of education, this empirical test differentiated between interpersonal and state-sanctioned violence to refine the socialization model. Although social scientists typically think of education as challenging authority and debunking inequality-legitimating myths such as racism and sexism, it also can legitimate stratification and some forms of authority. Research has shown that people will accept actions that they otherwise would perceive as unjust if such actions were carried out by a legitimate authority (Johnson et al. 2016). Therefore, the legitimation of stratification and state-sanctioned violence has important real-world consequences. The results reported in this study suggest that new approaches and target audiences may be needed in attempts to counter acceptance of and complacency toward police brutality and other forms of state-sanctioned violence in the United States.

\section{SUPPLEMENTARY MATERIAL}

To view supplementary material for this article, please visit https://doi.org/10.1017/S1049096518000094

\section{ACKNOWLEDGMENTS}

The author is grateful to the anonymous reviewers for their comments.

\section{NOTES}

1. See Schneider and Castillo (2015) for more recent findings in which more education is associated with positive views toward poor people even while higher income is negatively associated with these same issues. This pattern highlights the importance of controlling for income to determine whether patterns for education result from schooling or SES.

2. ALSOS is a method for estimating models without making arbitrary and ultimately unjustifiable assumptions about category spacing for ordinal outcomes (DeLeeuw, Young, and Takane 1976; Jacoby 2014). ALSOS provides best-fitting estimates of value points and individual vectors, thereby transforming categorical data with unequal spacing into linear data (Jacoby 1999; 2014). Coefficients for this method can be interpreted similarly to how OLS estimates would be interpreted because ALSOS transformation retains the original means and standard deviations of the untransformed variables. The optimal-scaling procedure was conducted using Armstrong's ALSOS R package.

3. The overall levels of support for the justifiability of family violence-12\% said beating a wife and $22 \%$ said beating children could ever be justifiable-skewed the distribution to the "never justifiable" response. Checks using alternative measurement and modeling strategies yielded similar patterns.

4. Coefficients for covariates are available on request.

5. I conducted additional analyses to consider the cognitive sophistication explanation for the effect of education on social attitudes (e.g., Bobo and Licari 1989). The WORDSUM variable available in the GSS-used by Makowsky and Miller (2014) and others to proxy intelligence-accounts for some of the relationship between education and attitudes, but substantial and significant education "effects" persist. Therefore, "cognitive sophistication" appears to play a role in the relationship between education and attitudes but, as Phelan and colleagues (1995) argued, not as large a role as socialization.

6. These patterns are consistent with Gross and Fosse's (2012) discussion of professors and political liberalism. Whereas college appears to socialize students into the dominant American culture, some types of graduate education-similar to acculturation into a sexual-minority identity (Lewis, Rogers, and Sherrill 2011)-socialize people into a subcultural identity and related subcultural values. I found confirmatory patterns for an additional item, the death penalty, which included a number of cases with "don't know" responses that if dropped would have decreased the sample size for the primary measures. Support for the death penalty was U-shaped and lowest among those with less than a high school education and those with a graduate degree.

7. As in most research, the measures used in this study were imperfect and the nature of the data allowed me to test only whether the patterns were consistent with the theory rather than definitively testing the theory. Therefore, future research should examine the legitimation of state-sanctioned violence in more detail and further test this refined socialization model. 


\section{REFEREN NES}

Adorno, Theodor, Else Frenkel-Brunswik, Daniel Levinson, and R. Nevitt Sanford. 1950. The Authoritarian Personality. Oxford, England: Harpers.

Bobo, Lawrence, and Frederick C. Licari. 1989. "Education and Political Tolerance." Public Opinion Quarterly 53 (3): 285-308.

Brenner, Philip S., Richard T. Serpe, and Sheldon Stryker. 2014. "The Causal Ordering of Prominence and Salience in Identity Theory: An Empirical Examination." Social Psychology Quarterly 77 (3): 231-52.

Brooks, Clem. 2006. "Voters, Satisficing, and Policymaking: Recent Directions in the Study of Electoral Politics.” Annual Review of Sociology 32: 191-211.

DeLeeuw, Jan, Forrest W. Young, and Yoshio Takane. 1976. "Additive Structures in Qualitative Data, an Alternating Least Squares Method with Optimal Scaling Features." Psychometrika 41 (4): 471-503.

Gibson, James L. 2013. "Measuring Political Tolerance and General Support for Pro-Civil Liberties Policies." Public Opinion Quarterly 77 (S1): 45-68.

Gross, Neil, and Ethan Fosse. 2012. "Why Are Professors Liberal?" Theory and Society 41 (2): 127-68.

Hyman, Herbert, and Charles Wright. 1979. Education's Lasting Influence on Values. Chicago: University of Chicago Press.

Jackman, Mary R. 1994. The Velvet Glove: Paternalism and Conflict in Gender, Class, and Race Relations. Berkeley: University of California Press.

Jackman, Mary R., and Michael J. Muha. 1984. "Education and Intergroup Attitudes: Moral Enlightenment, Superficial Democratic Commitment, or Ideological Refinement?" American Sociological Review 49 (6): 751-69.

Jacoby, William G. 1999. "Levels of Measurement and Political Research: An Optimistic View.” American Journal of Political Science 43 (1): 271-301.

. 2014. "Is There a Culture War? Conflicting Value Structures in American Public Opinion." American Political Science Review 108 (4): 1-18.

Johnson, Cathryn, Karen A. Hegtvedt, Nikki Khanna, and Heather L. Scheuerman. 2016. "Legitimacy Processes and Emotional Responses to Injustice." Social Psychology Quarterly 79 (2): 95-114.

Kingston, Paul W., et al. 2003. "Why Education Matters." Sociology of Education 76 (1): 53-70.

Lewis, Gregory B., Marc A. Rogers, and Kenneth Sherrill. 2011. "Lesbian, Gay, and Bisexual Voters in the 2000 US Presidential Election." Politics \& Policy 39 (5): 655-77.

Makowsky, Michael D., and Stephen C. Miller. 2014. "Education, Intelligence, and Attitude Extremity." Public Opinion Quarterly 78 (4): 832-58.

Page, Benjamin I., and Robert Y. Shapiro. 1992. The Rational Public: Fifty Years of Trends in Americans' Policy Preferences. Chicago: University of Chicago Press.

Phelan, Jo, Bruce G. Link, Ann Stueve, and Robert E. Moore. 1995. "Education, Social Liberalism, and Economic Conservatism: Attitudes Toward Homeless People." American Sociological Review 6o (1): 126-40.
Rokeach, Milton. 1960. The Open and Closed Mind: Investigations into the Nature of Belief Systems and Personality Systems. New York: Basic Books.

Schnabel, Landon, and Eric Sevell. 2017. "Should Mary and Jane Be Legal? Americans' Attitudes toward Marijuana and Same-Sex Marriage Legalization, 1988-2014." Public Opinion Quarterly 81 (1): 157-72.

Schneider, Simone M., and Juan C. Castillo. 2015. "Poverty Attributions and the Perceived Justice of Income Inequality: A Comparison of East and West Germany." Social Psychology Quarterly 78 (3): 263-82.

Selznick, Gertrude J., and Stephen Steinberg. 1969. The Tenacity of Prejudice. New York: Harper \& Row.

Smith, Tom W. 1984. "The Polls: Gender and Attitudes Toward Violence." Public Opinion Quarterly 48 (1): 384-96.

—. 1995. "Some Aspects of Measuring Education." Social Science Research 24 (3): 215-42.

Smith, Tom W., Peter Marsden, Michael Hout, and Jibum Kim. 2015. General Socia Surveys, 1972-2014 [Machine-Readable Data File]. Chicago: National Opinion Research Center.

Stets, Jan E., and Richard T. Serpe. 2013. "Identity Theory." In Handbook of Social Psychology, eds. J. DeLamater and A. Ward, 31-6o. New York: Kluwer-Plenum.

Stouffer, Samuel. 1955. Communism, Conformity, and Civil Liberties: A Cross-Section of the Nation Speaks Its Mind. Garden City, NY: Doubleday.

Stryker, Sheldon. 2008. "From Mead to a Structural Symbolic Interactionism and Beyond." Annual Review of Sociology 34 (1): 15-31.

Stubager, Rune. 2008. "Education Effects on Authoritarian-Libertarian Values: A Question of Socialization." British Journal of Sociology 59 (2): 327-50.

. 2009. "Education-Based Group Identity and Consciousness in the Authoritarian-Libertarian Value Conflict." European Journal of Political Research 48 (2): 204-33.

. 2010. "The Development of the Education Cleavage: Denmark as a Critical Case." West European Politics 33 (3): 505-33.

- 2013. "The Changing Basis of Party Competition: Education, AuthoritarianLibertarian Values and Voting." Government and Opposition 48 (3): 372-97.

Tajfel, Henri. 1978. "Social Categorization, Social Identity and Social Comparison." In Differentiation between Social Groups: Studies in the Social Psychology of Intergroup Relations, ed. Henri Tajfel, 61-76. London: Academic Press.

Weakliem, David L. 2002. "The Effects of Education on Political Opinions: An International Study." International Journal of Public Opinion Research 13 (2): 141-57.

Weil, Frederick D. 1985. "The Variable Effects of Education on Liberal Attitudes: A Comparative-Historical Analysis of Anti-Semitism Using Public Opinion Survey Data." American Sociological Review 50 (4): 458-74. 